\title{
Desempenho do amendoim forrageiro para revegetar argissolos degradados no norte fluminense
}

A degradação do solo é ocasionada por impactos negativos, que ocorrem no meio ambiente. Suas principais causas são originadas por ações antrópicas, como a agricultura malconduzida, ocasionando, por exemplo, a erosão. Uma das soluções para reduzir a degradação e seus malefícios é a revegetação, pois a mesma pode promover a recuperação do solo, reabilitando suas funções ecológicas, como a ciclagem de nutrientes. Entre as espécies utilizadas para a revegetação, as leguminosas se destacam, pois são capazes de promover a fixação biológica do nitrogênio, dentre essas, o amendoim forrageiro (Arachis pintoi). 0 trabalho teve como objetivo analisar o desempenho do amendoim forrageiro para revegetar o subsolo de um ARGISSOLO no norte fluminense, utilizando composto orgânico, adubação química convencional e controle. No experimento, utilizou-se o solo do horizonte $\mathrm{B}$ em vasos de $3 \mathrm{~L}$. No tratamento composto orgânico, utilizou-se $50 \mathrm{~g} / \mathrm{L}$, e na adubação convencional, 6,6g/L de superfosfato, e $0,6 \mathrm{~g} / \mathrm{L}$ de cloreto de potássio, e após 90 dias, características do solo e das plantas foram analisadas. Utilizouse o delineamento inteiramente casualizado. Os resultados para os parâmetros comprimento da haste, número de brotações e estimativa de matéria seca não apresentaram diferenças. Dados de produção de biomassa para o controle, composto orgânico e adubação química foram 9,33g/planta; $9,17 \mathrm{~g} / \mathrm{planta;} 8,2 \mathrm{~g} / \mathrm{planta}$, respectivamente. Os teores e conteúdos de nutrientes proporcionaram maiores valores com a adição de composto orgânico. Os resultados encontrados sugerem que o amendoim forrageiro apresente potencial para revegetar solos degradados. Em relação aos fertilizantes utilizados como tratamento no período de 90 dias, os resultados foram similares para as características vegetativas, mas houve aumento no conteúdo de nutrientes, o que pode significar que ao longo do tempo a ausência de adubação poderia comprometer o processo de crescimento das plantas, diminuindo a eficiência da revegetação quando utilizadas para recuperar áreas degradadas.

Palavras-chave: Recuperação de áreas degradadas; Leguminosas; Composto orgânico; Adubação.

\section{Performance of forage peanut to revegetate degraded argisols in north fluminense}

\begin{abstract}
Soil degradation is caused by negative impacts that occur on the environment. Its main causes are caused by anthropic actions, such as poorly conducted agriculture, causing, for example, erosion. One of the solutions to reduce degradation and its harms is revegetation, as it can promote soil recovery, rehabilitating its ecological functions, such as nutrient cycling. Among the species used for revegetation, legumes stand out because they are capable of promoting biological nitrogen fixation, among them the peanut forage (Arachis pintoi). The objective of this work was to analyze the performance of forage peanut to revegetate the soil of an ARGISSOLO in the north of Rio de Janeiro state, using organic compost, conventional chemical fertilization and control. In the experiment, horizon B soil was used in $3 \mathrm{~L}$ pots. In the organic compound treatment, $50 \mathrm{~g} / \mathrm{L}$ was used, and in the conventional fertilization, $6,6 \mathrm{~g} / \mathrm{L}$ of superphosphate, and $0,6 \mathrm{~g} / \mathrm{L}$ of potassium chloride, and after 90 days, soil and plant characteristics were analyzed. A completely randomized design was used. The results for the stem length, number of shoots and dry matter estimation parameters did not differ. Biomass production data for control, organic compost and chemical fertilization were $9,33 \mathrm{~g} / \mathrm{plant}$ $9,17 \mathrm{~g} / \mathrm{plant} ; 8,2 \mathrm{~g} / \mathrm{plant}$, respectively. Nutrient contents and contents provided higher values ??with the addition of organic compost. The results suggest that forage peanuts have potential to revegetate degraded soils. In relation to the fertilizers used as treatment in the 90 days period, the results were similar for the vegetative characteristics, but there was an increase in the nutrient content, which may mean that over time the lack of fertilization could compromise the growth process. plants, reducing revegetation efficiency when used to recover degraded areas.
\end{abstract}

Keywords: Recovery of degraded areas; Legumes; Organic compost; Fertilizing.

\section{Topic: Engenharia Ambiental}

Reviewed anonymously in the process of blind peer.
Received: 05/03/2019

Approved: 11/06/2019

Ershiley Pereira David Fortunato (id

Instituto Federal Fluminense, Brasil

http://lattes.cnpq.br/9360665623327273

http://orcid.org/0000-0001-6595-7207

ershiley22@gmail.com

d.

DOI: 10.6008/CBPC2237-9290.2019.002.0002
Referencing this:

FORTUNATO, E. P. D.. Desempenho do amendoim forrageiro para revegetar argissolos degradados no norte fluminense. Natural Resources, v.9, n.2, p.9-18, 2019. DOI:

http://doi.org/10.6008/CBPC2237-9290.2019.002.0002 


\section{INTRODUÇÃO}

A degradação do solo está relacionada à existência e ocupação humana do planeta, e vem crescendo desde tempos antigos até as modernas tecnologias de produção e exploração utilizadas pelo homem. Segundo a FAO (2015), mais de 33\% dos solos no mundo apresentam degradação moderada a alta, ocasionada por fatores como a má gestão do solo e água, gerando consequências como erosão, acidificação, salinização etc.

No Brasil, a degradação do solo já atingiu cerca de 140 milhões de hectares, uma área superior ao tamanho de duas Franças e vem crescendo cada vez mais com o uso desenfreado desse recurso natural, sem o cumprimento das medidas que visam diminuir tais impactos negativos (BRASIL, 2018). No Estado do Rio de Janeiro, cerca de $16 \%$ do solo já apresenta perda considerável da biodiversidade e de suas principais características físicas e químicas. A agricultura malconduzida e a erosão são os principais fatores no norte fluminense que causam a degradação prejudicando de forma quase irreversível sua formação original (BRASIL, 2018).

Uma solução utilizada para reduzir esses impactos é a revegetação, pois essa prática pode promover a recuperação do solo e reabilitar as funções ecológicas do ecossistema. A revegetação tem por finalidade recuperar as características de um determinado local que sofreu degradação, evitando ou diminuindo a erosão e deslizamentos, adicionando matéria orgânica possibilitando o retorno dos organismos, e melhorando as características químicas e físicas do solo. A revegetação irá reabilitar importantes funções anteriormente exercidas pela cobertura vegetal original.

Estudos já mostram o bom desempenho das leguminosas em recuperar solos degradados. Segundo Ludwig (2010), as leguminosas promovem benefícios ao introduzir o nitrogênio fixado biologicamente no solo, o que reduz os custos com o uso de fertilizantes, além de apresentar uma elevada produção de matéria seca de boa qualidade. As leguminosas também apresentam raízes com boa profundidade e arquitetura ideal para estabilização do solo, recuperação da capacidade produtiva, e diminuição da erosão.

O amendoim forrageiro (Arachis pintoi), ao contrário das espécies de leguminosas tropicais, apresenta o ponto de crescimento protegido, o que permite a manutenção da cobertura vegetal, sendo por isso a espécie a ser utilizada nesse estudo. O objetivo desse trabalho foi avaliar o desempenho do amendoim forrageiro para revegetar um subsolo de um ARGISSOLO no norte fluminense, nos tratamentos sem adubação (controle), com composto orgânico, e com a utilização de adubação química convencional.

\section{METODOLOGIA}

O experimento foi conduzido em casa de vegetação com sombrite de $50 \%$, irrigação diária auxiliada por uma mangueira para o desenvolvimento das plantas. A casa de vegetação pertence ao Instituto Federal Fluminense campus Bom Jesus do Itabapoana. A cidade se localiza no Noroeste do estado e está situada a $21^{\circ} 08^{\prime \prime} 02^{\prime \prime \prime \prime}$ de latitude sul e $41^{\circ} 40^{\prime \prime} 47^{\prime \prime \prime}$ de longitude. A altitude é de 88 metros; o clima, do tipo Aw tropical 
subúmido e seco, segundo Köppen, com temperatura anual de $23,6^{\circ} \mathrm{C}$ e precipitação média anual de $1101 \mathrm{~mm}$.

Os propágulos do amendoim forrageiro (Arachis pintoi) cedidos pela Embrapa Agrobiologia em Seropédica (RJ) foram umedecidos e armazenados em local sombreado por quatro dias. Após esse período, segmentos de caule de $20 \mathrm{~cm}$ foram colocados para enraizar em copos descartáveis de $200 \mathrm{ml}$ (reutilizados), utilizando um substrato formado por duas partes de solo arenoso e duas partes de composto orgânico com três gemas na parte aérea e duas no solo. Os propágulos foram regados diariamente e ali permaneceram por 62 dias até a formação das mudas. Essa etapa foi realizada no campus Guarus do IFF na cidade de Campos dos Goytacazes (RJ).

Após o enraizamento, as mudas foram encaminhadas para o campus Bom Jesus do Itabapoana do IFF, localizada na cidade de Bom Jesus do Itabapoana (RJ). Para a condução do experimento, foi selecionada a classe mais representativa da região denominada Argissolo Vermelho-Amarelo, que foi coletada a uma profundidade entre 20 e $40 \mathrm{~cm}$ e depois peneirada, sendo encaminhada para o setor de produção de mudas, onde se iniciou a montagem nos vasos para os três tratamentos diferentes.

Os tratamentos foram: somente o subsolo; subsolo com adição de $50 \mathrm{~g} / \mathrm{L}$ de composto orgânico, elevando o teor de matéria orgânica a aproximadamente $20 \mathrm{~g} / \mathrm{dm}^{3}$; subsolo com adubação química com 6,6g/L de superfosfato simples; e $0,6 \mathrm{~g} / \mathrm{L}$ de cloreto de potássio. Após preencher os vasos com o subsolo Argissolo Vermelho-Amarelo, retiraram-se as mudas dos copos plásticos e inseriu-as a uma profundidade de 5 a $10 \mathrm{~cm}$ em cada repetição padronizando-as com o auxílio de uma régua graduada a uma altura de $10 \mathrm{~cm}$. Os vasos contendo os tratamentos foram encaminhados para a casa de vegetação onde permaneceram por um período de 90 dias.

O delineamento experimental utilizado foi o inteiramente casualizado, com seis repetições para os três tratamentos citados, totalizando 18 vasos. Nos 30, 60 e 90 dias, analisaram-se características morfológicas, como o comprimento das hastes, com o auxílio de uma régua graduada $\mathrm{em} \mathrm{cm}$, da base do coleto até a parte final da espécie Arachis pintoi considerando as hastes com comprimento superior a $10 \mathrm{~cm}$, e o número de brotações através da contagem a olho nu.

Após os 90 dias de condução do experimento, realizou-se a pesagem da matéria seca, com o corte e armazenamento das plantas em sacos de papel pardo que foram encaminhadas para o Laboratório de Meio Ambiente do campus Guarus do IFF, e colocadas em uma estufa com circulação forçada a $80^{\circ} \mathrm{C}$ por 72 horas. Após a secagem, utilizou-se uma balança digital para determinar o peso da matéria seca.

Após a pesagem, retirou-se uma haste de cada repetição, formando uma amostra composta para cada tratamento, e foram encaminhadas para o Laboratório da Fundação Norte Fluminense de Desenvolvimento Regional (FUNDENOR), cujas as análises seguiram a metodologia recomendada pelo Instituto Capixaba de pesquisa, Assistência técnica e Extensão Rural (INCAPER) para obter os teores de nutrientes (PREZOTTI et al., 2013). 


\section{RESULTADOS E DISCUSSÃO}

Para a característica comprimento das hastes não se observou diferenças significativas entre os tratamentos $(P>0,05)$, como mostra a figura 1. Observou-se que, aos 90 dias após o plantio, para a característica comprimento da haste as médias, foram de $69,7 \mathrm{~cm}$ para controle; $53,8 \mathrm{~cm}$ para composto orgânico; e $52 \mathrm{~cm}$ para adubação química. Os tratamentos não diferiram entre si, sugerindo que para o comprimento da haste o amendoim forrageiro inicialmente não foi influenciado pela adição de potássio e fósforo, assim como pela adição de composto orgânico.

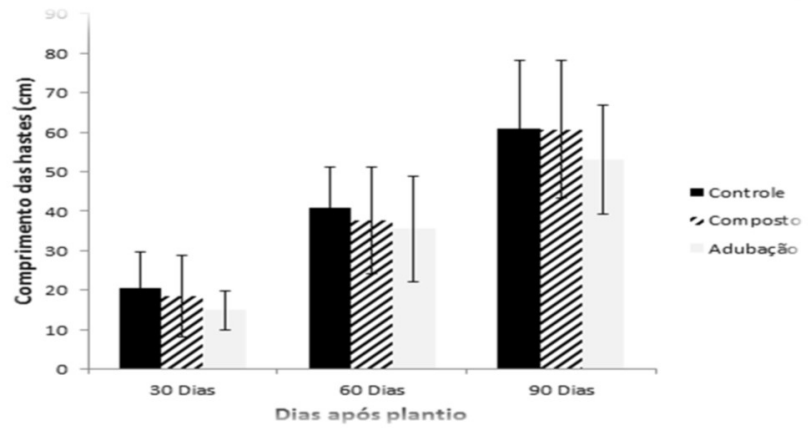

Figura 1: Comprimento das hastes nos 30,60 e 90 dias de experimento. O intervalo de confiança $(P>0,05)$ está representado pelas barras.

Andrade et al. (1999) encontrou, para o comprimento da haste, a média de 92,86cm após 150 dias, nas condições de $50 \%$ de sombreamento, condição similar ao presente experimento. Os menores valores observados para esta característica neste trabalho podem ser explicados pelo menor tempo de condução. Oliveira et al. (2003), em Seropédica, obteve médias de $45,8 \mathrm{~cm}$ (sombrite $25 \%$ ) e 108,3cm (sombrite 50\%) em 175 dias. Semelhante a este trabalho os tratamentos não diferiram estatisticamente.

Valentim et al. (2003), ao realizar uma avaliação da velocidade de estabelecimento de acessos de amendoim forrageiro na Amazônia em Rio Branco (AC), obteve uma altura de $62 \mathrm{~cm}$ após 120 dias de experimento no período entre maio a setembro. Teixeira et al. (2010) avaliou leguminosas forrageiras nas condições ambientais do município de Itambé (Pernambuco), e cita valor médio de altura para Arachis pintoi de $74 \mathrm{~cm}$ aos 102 dias após o plantio. Ressalta-se que na implantação do experimento, os autores utilizaram mudas produzidas em casa de vegetação semelhante a este trabalho, para depois transplantá-las ao campo. Para a característica número de brotações não se observou diferença entre os tratamentos (figura 2).

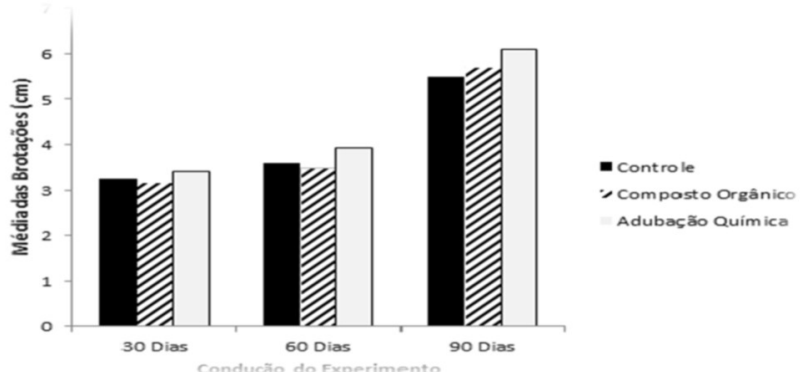

Figura 2: Média dos números de brotações realizada em casa de vegetação com sombrite $50 \%$ nos 30,60 e 90 dias de experimento. 
A tendência maior no número de brotações na adubação química pode estar relacionada à adição de fósforo que é um nutriente que atua de forma intensa na atividade meristemática, ajudando assim na produção de sementes e mais rápida floração (WHITEHEAD, 2000). Os resultados obtidos pela produção de matéria seca (MS) em cada vaso estão apresentados na figura 3. A análise da variância mostrou que não houve diferenças significativas entre os tratamentos. Os dados de matéria seca por planta em cada vaso foram utilizados para estimar a produção de matéria seca em diferentes espaçamentos (tabela 1), para simular possíveis rendimentos em condições de plantio.

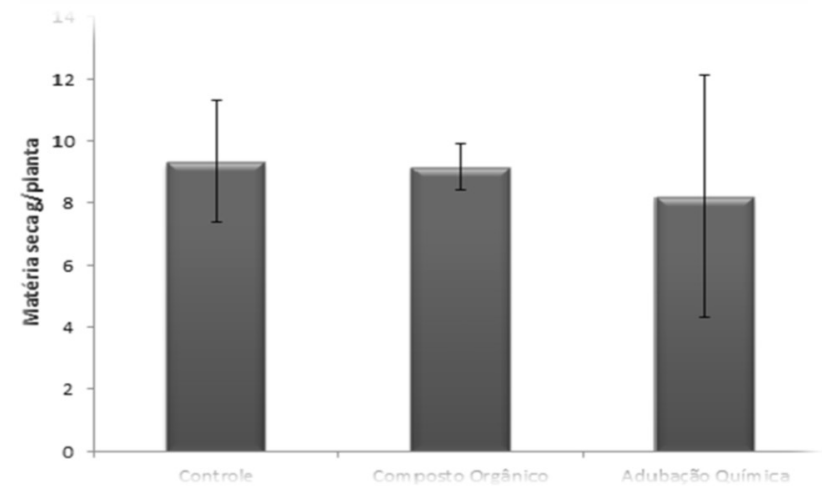

Figura 3: Produção média de matéria seca por planta do amendoim forrageiro aos 90 dias após plantio, em vasos de $3 \mathrm{~L}$ com substrato de ARGISSOLO. As barras representam o intervalo de confiança $(P>0,05)$.

Tabela 1: Estimativa da produção de matéria seca para o amendoim forrageiro em diferentes espaçamentos, a partir dos dados obtidos neste trabalho.

\begin{tabular}{|l|l|l|l|l|}
\hline \multicolumn{5}{|c|}{ Estimativa da produtividade de matéria seca } \\
\hline Espaçamento & Plantas/ha & Controle & Composto Org. & Adubação Quim. \\
\hline $0,25 \times 0,25 \mathrm{~m}$ & 160.000 & 1493 & 1467 & 1312 \\
\hline $0,25 \times 0,5 \mathrm{~m}$ & 80.000 & 746 & 733 & 656 \\
\hline $0,5 \times 0,5 \mathrm{~m}$ & 40.000 & 372 & 367 & 328 \\
\hline
\end{tabular}

Os resultados observados por Machado (2004), em um ano e três meses de experimento nos espaçamentos entre plantas e entre linhas de 0,25 x 0,25m e 0,5 x 0,5m, produziram $7132 \mathrm{~kg} / \mathrm{ha}$ e 3107 $\mathrm{kg} / \mathrm{ha}$, respectivamente. Quando se fixou o espaçamento entre plantas de 0,5m para 0,25m, obteve-se um acréscimo de 69\% na produção de matéria seca. Fixado o espaçamento entre linhas de 0,25m, e entre plantas de $0,5 \mathrm{~m}$ essa produção subiu para 59\%, mostrando que ao trocar os espaçamentos maiores pelos menores e intercalar os mesmos ocasionou em um acréscimo.

Machado (2004) considerou, ainda, em seu experimento, populações equivalentes a 40.000 plantas/ha no espaçamento $05 \times 0,5 \mathrm{~m}$ e 160.000 plantas/ha no espaçamento $0,25 \times 0,25 \mathrm{~m}$, onde o maior espaçamento $(0,5 \mathrm{~m})$ não produziu cobertura efetiva e proteção do solo, sendo menos interessantes sob aspecto de matéria seca, fato este também observado em tremoço por Benassi et al. (1991).

De acordo com Pizarro et al. (1994), as maiores áreas estimadas são as que menos produzem matéria seca, e ao realizaram um estudo em oito meses com espaçamentos 0,25 x 0,25m; 0,5 x 0,5m; 0,75 x 0,75m; $1,0 \times 1,0 \mathrm{~m}$ apresentaram produção de $7040 \mathrm{~kg} / \mathrm{ha} ; 3020 \mathrm{~kg} / \mathrm{ha} ; 2160 \mathrm{~kg} / \mathrm{ha}$ e $2080 \mathrm{~kg} / \mathrm{ha}$, respectivamente. Isso comprova que os espaçamentos menores entre linhas e plantas são mais eficazes na formação de forragem e produção de matéria seca de acordo com essas estimativas, fato comprovado por Rao et al. (1993), ao 
observar que o espaçamento das plantas entre linhas e entre plantas são fatores determinantes na produção de matéria seca, sendo essencial para a massa de forragem onde plantas dispostas entre linhas $0,25 \mathrm{~m}$ apresentaram maiores rendimentos.

Os resultados da análise de nutrientes da parte aérea do amendoim forrageiro, colhida aos 90 dias após o plantio, estão expressos na tabela 2. Observa-se que a adição de composto orgânico proporcionou os maiores teores de N, K, Ca, Fe e Zn (tabela 2). Enquanto, a adição de superfosfato simples e cloreto de potássio, conforme o esperado, proporcionou teores mais elevados de $\mathrm{P}$, S e K. Destaca-se que, mesmo não adicionando uma fonte de $\mathrm{N}$ na adubação química, seus teores estão próximos aos valores observados para a adição de composto orgânico, que é uma fonte de N. Por outro lado, o teor de K observado para o composto está acima do observado para a adição de adubação potássica.

Raij (1991), ao realizar um estudo em Argissolos Vermelhos-Escuro e Argissolo Vermelho-Amarelo, observou que o composto orgânico apresentou maiores teores de nutrientes em relação aos demais tratamentos, porque a matéria orgânica servia como fonte de reserva, aumentando, assim, as concentrações de macro e micronutrientes nesses solos, o mesmo observado nesse estudo. Stockdale et al. (2002) observou que a adubação com matéria orgânica em amendoim forrageiro era a principal reserva de nitrogênio no solo, com grande significado para o suprimento dos demais nutrientes para as culturas.

Jones et al. (1977) observou que a adubação fosfatada e o enxofre influenciavam a nodulação de leguminosas, aumentando o número de nódulos por planta e o tamanho dos nódulos. Werner (1984) observou que para as leguminosas o aumento de potássio, além de afetar de forma positiva o crescimento da planta, aumentava também a nodulação (número e tamanho de nódulos), proporcionando melhor fixação de nitrogênio, justificando seu elevado teor na adubação química.

Tabela 2: Concentração de nutrientes na parte aérea do amendoim forrageiro, aos 90 dias após plantio, cultivado em vasos de 3L contendo subsolo (prof. 20-40) Argissolo Vermelho-Amarelo. Os valores entre parênteses representam a diferença percentual em relação ao controle.

\begin{tabular}{|c|c|c|c|c|c|c|c|c|c|c|}
\hline & $\mathrm{N}$ & $\mathrm{S}$ & $P$ & $\mathrm{~K}$ & $\mathrm{Ca}$ & $\mathrm{Mg}$ & $\mathrm{Fe}$ & $\mathrm{Cu}$ & $\mathrm{Zn}$ & $\mathrm{Mn}$ \\
\hline & \multicolumn{6}{|c|}{$\mathrm{g} / \mathrm{Kg}$} & \multicolumn{4}{|c|}{$-\mathrm{g} / \mathrm{dm}^{3}$} \\
\hline \multicolumn{11}{|l|}{ Tratamentos } \\
\hline Controle & 16,5 & 1,8 & 2,5 & 16,8 & 12,1 & 4,1 & 260 & 8 & 30 & 810 \\
\hline \multirow[t]{2}{*}{ Composto Orgânico } & 31,2 & 2,5 & 2,6 & 19,4 & 16,0 & 3,8 & 520 & 4 & 32 & 166 \\
\hline & $(89 \%)$ & $(39 \%)$ & $(4 \%)$ & $(15 \%)$ & $(32 \%)$ & $(7 \%)$ & $(100 \%)$ & $(50 \%)$ & $(7 \%)$ & $(80 \%)$ \\
\hline \multirow[t]{2}{*}{ Adubação Química } & 29,4 & 4,2 & 3,4 & 18,8 & 14,8 & 3,3 & 190 & 6 & 24 & 720 \\
\hline & (78\%) & (133\%) & (36\%) & $(12 \%)$ & (22\%) & (20\%) & $(27 \%)$ & (25\%) & (20\%) & $(11 \%)$ \\
\hline
\end{tabular}

O amendoim forrageiro cultivado em Argissolos pode necessitar de adubações, de acordo com as características observadas na análise química do solo, por ser uma forrageira com lento desenvolvimento no início (EMBRAPA, 2006). A ausência de adubações pode refletir em baixas concentrações de nutrientes (INCAPER, 2013), conforme observado neste trabalho.

Em relações aos teores de $\mathrm{N}$, resultados similares foram observados por Batista (2006), com 35,5g/kg, $28,9 \mathrm{~g} / \mathrm{kg}$ e $27,6 \mathrm{~g} / \mathrm{kg}$ composto, adubação fosfatada e testemunha, respectivamente. Alguns trabalhos sugerem que o $\mathrm{S}$ auxilia no crescimento dos nódulos do amendoim forrageiro, o que pode ajudar a explicar os teores de $\mathrm{N}$ na adubação química próxima ao do composto orgânico. 
A elevada concentração de $S$ na adubação química se deve a adição desse nutriente no superfosfato (10\%). O valor de P observado no tratamento com adubação química está de acordo com o que foi visto por Souza et al. (2003), onde as adubações fosfatada e potássica resultaram em um aumento nos teores de P (de 1,5g/kg para 3,6g/kg) disponíveis no solo. Góis et al. (1997) observou o efeito positivo da adubação química fosfatada sobre a velocidade de estabelecimento e produção de matéria seca do amendoim forrageiro.

O teor de K nas plantas que estavam com composto é verificado por Claassens (1994), onde houve um aumento no teor de $\mathrm{K}$ ao elevar o fornecimento da compostagem no solo agregando a produção de matéria seca em leguminosas e por Kano (2006) utilizando a Arachis pintoi. O Ca em plantas adubadas com composto, foi visto também por Castelán et al. (2000), onde o cálcio foi o macronutriente de maior concentração ao ser adubado com matéria orgânica $(15,8 \mathrm{~g} / \mathrm{kg})$.

O magnésio observado no tratamento controle, foi verificado por Costa et al. (2007), ao realizarem um estudo com o amendoim forrageiro em solos arenosos e argissolos degradados, e obtiveram um teor de magnésio de $4,8 \mathrm{~g} / \mathrm{kg}$ e $5,4 \mathrm{~g} / \mathrm{kg}$, respectivamente. Valores um pouco superiores aos observados neste trabalho, porém, ressalta-se que foi utilizado subsolo geralmente mais pobre em nutrientes.

O elevado teor de ferro observado para a adubação química foi visto também por Prezotti et al. (2013), ao afirmarem que o ferro é geralmente abundante em solos tropicais (arenosos e argissolos), o que pôde ser verificado no presente estudo. Nos tratamentos composto e controle, os teores de ferro apresentaram-se muito acima do esperado (INCAPER, 2013), fato também observado por Lima et al. (2010), no qual esse micronutriente em leguminosas consorciadas apresentou teor $107 \%$ acima do teor ideal, explicando-se pelas expressivas concentrações de ferro em solos brasileiros.

Os teores de zinco observados no tratamento com composto estão de acordo com o observado por KIEHL (2002), em estudo com folhas de amendoim forrageiro no qual este elemento apresentou maior valor $(28 \mathrm{~g} / \mathrm{kg})$. O manganês observado na parte aérea da planta que crescia no composto, não apresentou elevado teor (INCAPER, 2013) como os demais tratamentos, porque segundo Prezotti et al. (2013), solos adubados com matéria orgânica formam complexos orgânicos que reduzem a disponibilidade desse micronutriente, que assim como o ferro é abundante em solos tropicais.

Para a adubação química e controle, a concentração de manganês apresentou-se muito acima do esperado (INCAPER, 2013), fato observado por Veloso et al. (1995), onde esse micronutriente possuía quantidades elevadas nos tecidos das plantas, causando o excesso do mesmo o que acarretou em níveis tóxicos afetando as raízes, folhas, etc.. O valor do cobre no tratamento sem adubação, também foi observado por Ribeiro et al. (2011), ao sugerir que argissolos com leguminosas forrageiras apresentaram resultados superiores de cobre $(7,0 \mathrm{~g} / \mathrm{kg})$ ao possuírem alta concentração desse micronutriente, não necessitando de adubações inicialmente.

A faixa de valores observados para os teores de Fe e Mn encontram-se acima dos teores considerados adequados (INCAPER, 2013), o que se explica pela elevada concentração destes micronutrientes no solo (tabela 3) que apresentaram concentrações de $\mathrm{Fe}-22,6 \mathrm{mg} / \mathrm{dm}^{-3}$ e $\mathrm{Mn}-41,4 \mathrm{mg} / \mathrm{dm}^{-3}$, no qual o ferro apresentou disponibilidade média $\left(20-45 \mathrm{mg} / \mathrm{dm}^{-3}\right)$ e o manganês disponibilidade acima $\left(>12 \mathrm{mg} / \mathrm{dm}^{-3}\right)$. Os 
conteúdos de macronutrientes aos 90 dias após o plantio estão descritos na tabela 3. A adição de composto orgânico proporcionou o aporte das maiores quantidades de nutrientes N, S, P, K, Ca em relação à adubação química e controle.

Tabela 1: Quantidade de macronutrientes na parte aérea do amendoim forrageiro, aos 90 dias após plantio, cultivado em vasos de $3 \mathrm{~L}$ contendo subsolo (prof. 20-40) Argissolo Vermelho-Amarelo.

\begin{tabular}{|c|c|c|c|c|c|c|}
\hline & $\mathrm{N}$ & $\mathrm{S}$ & $\mathrm{P}$ & $\mathrm{K}$ & $\mathrm{Ca}$ & $\mathrm{Mg}$ \\
\hline & \multicolumn{6}{|c|}{ g/planta } \\
\hline \multicolumn{7}{|l|}{ Tratamentos } \\
\hline Controle & 0,15 & 0,017 & 0,023 & 0,17 & 0,11 & 0,04 \\
\hline Composto Orgânico & 0,29 & 0,023 & 0,024 & 0,18 & 0,15 & 0,035 \\
\hline Adubação Química & 0,24 & 0,03 & 0,028 & 0,15 & 0,12 & 0,027 \\
\hline
\end{tabular}

Resultados de experimentos mostraram que a matéria orgânica proporcionou aumentos no aporte de nutrientes pela biomassa da parte aérea em cultivos de amendoim forrageiro (REIS JÚNIOR et al., 2001; MONTOYA et al., 2002). Silva (1998) encontrou, aos 275 dias, em um experimento com Arachis pintoi, um conteúdo do nutriente (K) por planta de $87 \mathrm{~g} /$ planta; $154 \mathrm{~g} /$ planta, respectivamente, para adubação química e composto. A estimativa da quantidade de nutrientes a ser exportada em diferentes espaçamentos é mostrada na tabela 4

Tabela 4: Estimativa da exportação de nutrientes em diferentes espaçamentos, para o amendoim forrageiro na idade de 90 dias após o plantio em horizonte B de Argissolo Vermelho-Amarelo.

\begin{tabular}{|c|c|c|c|c|c|c|c|}
\hline Espaçamento & Tratamentos & $\mathrm{N}$ & $S$ & $\mathrm{P}$ & $\mathrm{K}$ & $\mathrm{Ca}$ & $\mathrm{Mg}$ \\
\hline & & & & & $\mathrm{g} / \mathrm{ha}$ & & - \\
\hline \multirow[t]{3}{*}{$0,25 \times 0,25 \mathrm{~m}$} & Controle & 24 & 2,72 & 3,68 & 27,2 & 17,6 & 6,4 \\
\hline & Composto Orgânico & 46,4 & 3,68 & 3,84 & 28,8 & 24 & 5,6 \\
\hline & Adubação Química & 38,4 & 4,8 & 4,48 & 24 & 19,2 & 0,43 \\
\hline \multirow[t]{3}{*}{$0,25 \times 0,5 \mathrm{~m}$} & Controle & 12 & 1,36 & 1,84 & 13,6 & 8,8 & 3,2 \\
\hline & Composto Orgânico & 23,2 & 1,84 & 1,92 & 14,4 & 12 & 2,8 \\
\hline & Adubação Química & 19,2 & 2,4 & 2,24 & 12 & 9,6 & 0,22 \\
\hline \multirow[t]{3}{*}{$0,5 \times 0,5 \mathrm{~m}$} & Controle & 6 & 0,68 & 0,92 & 6,8 & 4,4 & 1,6 \\
\hline & Composto Orgânico & 11,6 & 0,92 & 0,96 & 7,2 & 6 & 1,4 \\
\hline & Adubação Química & 9,6 & 1,2 & 1,12 & 6 & 4,8 & 0,11 \\
\hline
\end{tabular}

No estudo realizado por Machado (2004), o aumento no acúmulo dos macronutrientes em função das densidades de plantas foi decorrente da variação da produção de matéria seca por hectare. O acúmulo máximo desses nutrientes foi encontrado no menor espaçamento de 0,25 x 0,25m ( $\mathrm{N}=14,59$ e S=80,10kg/ha, $\mathrm{P}=70,90 \mathrm{~kg} / \mathrm{ha} ; \mathrm{K}=65,79 \mathrm{~kg} / \mathrm{ha} ; \mathrm{Ca}=45 \mathrm{~kg} / \mathrm{ha} ; \mathrm{Mg}=32,4 \mathrm{~kg} / \mathrm{ha})$ com 160.000 plantas/ha, seguido do espaçamento $0,25 \times 0,5 \mathrm{~m}$, sendo $\mathrm{N}=11,4 \mathrm{~kg} / \mathrm{ha} ; \mathrm{S}=67 \mathrm{~kg} / \mathrm{ha} ; \mathrm{P}=58,5 \mathrm{~kg} / \mathrm{ha} ; \mathrm{K}=45,3 \mathrm{~kg} / \mathrm{ha} ; \mathrm{Ca}=26 \mathrm{~kg} / \mathrm{ha}$; $\mathrm{Mg}=21,8 \mathrm{~kg} / \mathrm{ha}$ com 40.000 plantas/ha. E para o espaçamento $0,5 \times 0,5$, as médias foram $\mathrm{N}=8,6 \mathrm{~kg} / \mathrm{ha}$; $\mathrm{S}=54,3 \mathrm{~kg} / \mathrm{ha} ; \mathrm{P}=47,8 \mathrm{~kg} / \mathrm{ha} ; \mathrm{K}=34,4 \mathrm{~kg} / \mathrm{ha}$; $\mathrm{Ca}=18 \mathrm{~kg} / \mathrm{ha} ; \mathrm{Mg}=13,1 \mathrm{~kg} / \mathrm{ha}$ com 10.000 plantas/ha. Perin et al. (2000) cita valores entre 37 e $247 \mathrm{~kg} /$ ha total de macronutrientes ( N, S, P, K, Ca, Mg) em exportação no espaçamento 0,25 x 0,25m, acumulados em dois anos a partir de 20 toneladas de matéria seca/ha.

\section{CONCLUSÕES}

Para as características comprimento da haste, número de brotações e estimativa de matéria seca não se observou diferenças entre os tratamentos. A adição de composto orgânico proporcionou maiores 
teores de N, K, Ca, Fe e Zn, provavelmente pela atuação da matéria orgânica como fonte reserva de nutrientes. A adubação química com a adição de superfosfato e cloreto de potássio apresentaram maiores proporções nos teores de S (10\% na composição do superfosfato) e P (fósforo adicionado). O K do cloreto de potássio apresentou menor proporção em relação ao composto pela ação da matéria orgânica (reserva).

Os teores de Mg e Cu para o controle, sugere que esses micronutrientes em subsolos mais pobres apresentam maiores concentrações, não necessitando inicialmente de fertilizantes. Os resultados encontrados sugerem o potencial do amendoim forrageiro para revegetar argissolos degradados, com o subsolo exposto. Nesse contexto, a ausência de adubação apresentou crescimento similar aos tratamentos com fertilizantes no período de 90 dias, porém ao longo do tempo a não adição de nutrientes poderá comprometer a revegetação.

\section{REFERÊNCIAS}

ANDRADE, C. M. S.; VALENTIM, J. F.. A produtividade e persistência de Arachis pintoi submetido a diferentes níveis de sombreamento. Revista Brasileira de Zootecnia, Viçosa, v.28, n.3, p.439-445, 1999. DOI:

http://doi.org/10.1590/S1516-35981999000300001

BATISTA, K.. Nitrogênio e enxofre na implantação do capimmarandu em substituição ao capim-braquiaria em degradação num solo com baixa matéria orgânica. Tese (Doutorado em Agronomia) - Universidade de São Paulo, Piracicaba, 2006.

BENASSI, A. C.; ABRAHAO, J. T. M.. Épocas de semeadura e espaçamentos sobre a produção de fitomassa de tremoco. Pesquisa Agropecuária Brasileira, Brasília, v.26, n.9, p.15171522, 1991.

BRASIL. Ministério do Meio Ambiente. Ministério vai recuperar áreas degradadas no MA: novas unidades de recuperação de áreas degradadas (urad) vão beneficiar comunidade de Santa Luzia e município de Chapadinha, no Maranhão. Brasília: MMA, 2018.

CASTELAN, E. B.; SILVA, A. S.; VILLARREAL, E. R. L.; TARBOURIECH, S.. Regional pole placement by output feedback for a class of descriptor systems. In: TRIENNIAL WORLD CONGRESS OF IFAC, 15. Annals. Barcelona: 2002.

CLAASSENS, A. S.. Influence of varying phosphorus supply on the growth and phosphorus composition of lettuce. Communication in Soil Science and PlantAnalysis, New York, v.25, n.9, p.1209-1221, 1994.

COSTA, N. L.; PAULINO, V. T.; TOWNSEND, C. R.; MAGALHAES, J. A.. Resposta de Arachis pintoi cv. Amarillo a níveis de fosforo. Revista de Biologia e Ciências da Terra, v.6, n.1, 2007.

EMBRAPA. Empresa Brasileira de Pesquisa Agropecuária. Sistema brasileiro de classificação de solos. 2 ed. Rio de Janeiro: Embrapa, 2006.

FAO. Food and Agriculture Organization. Status of the World's Soil Resources (SWSR): Main Report. Rome: FAO, 2015.
GOIS, S. L. L.; VILELA, L.; PIZARRO E. A.. Efeito de calcário, fósforo e potássio na produção de forragem de Arachis pintoi. Pasturas Tropicales, Cali, v.19, n.3, p.9-13, 1997.

INCAPER. Instituto Capixaba de Pesquisa, Assistência Técnica e Extensão Rural. Guia Interpretação análise do solo e foliar. Vitória: INCAPER, 2013.

JONES, G. D.; LUTZ JUNIOR, J. A.; SMITH, T. J.. Effects of phosphorus and potassium on soybean nodules and seed yield. Agronomy Journal, v.69, n.6, p.1003-1006, 1977.

KANO, C.. Doses de fosforo no acúmulo de nutrientes, na produção e na qualidade de sementes de alface. Tese (Doutorado em Agronomia e Horticultura) - Universidade Estadual Paulista, Botucatu, 2006.

KIEHL, E. J.. Manual de compostagem: maturação e qualidade do composto. Piracicaba: 2002.

LIMA, A. A.; ANDRADE, C. M. S.; SALES, M. F. L.. Efeito de doses de fosforo e potássio no estabelecimento de áreas de produção de sementes de Arachis pintoi BRA-040550. In: REUNIÃO ANUAL DA SOCIEDADE BRASILEIRA DE ZOOTECNIA, 47. Anais. Salvador: SBZ, 2010.

LUDWIG, R. L.. PRODUÇÃO E QUALIDADE DO Arachis pintoi. Enciclopédia Biosfera, Goiânia, v.6, n.11, p.1-15, 2010.

MACHADO, A. N.. Rendimento do amendoim-forrageiro estabelecido sob diferentes arranjos populacionais de plantas em planossolo. Ciência Animal Brasileira, São Paulo, v.6, n.3, p.151-162, 2004.

MONTOYA, R. B.; SPINOIA, A. G.; GARCIA, P. S.; PAREDES, D. G.. Demanda de potássio de tomate tipo saladette. Terra, v.20, p.391-399, 2002.

OLIVEIRA, F. L.; SOUTO, S. M.. Estabelecimento de leguminosas forrageiras tropicais na sombra. Pasturas Tropicales, Cali, v.25, n.3, p.13-17, 2003.

PERIN, A.; TEXEIRA, M. G. M.; GUERRA, J. G. M.. Formação de cobertura viva de solo com amendoim forrageiro a partir de diferentes densidades e espaçamentos entre sulcos de plantio. Seropédica: EMBRAPA, 2000. 
PIZARRO, E. A.; RINCON, A.. Regional experiences with forage Arachis in South America. In: KERRIDGE, P. C.; HARDY, B.. Biology and agronomy of forage Arachis. Cali: CIAT, 1994. p.144-157.

PREZOTTI, L. C.. Guia de interpretação de análise de solo e foliar. Vitória: INCAPER, 2013.

RAIJ, B.. Fertilidade do solo e adubação. Piracicaba: Ceres, 1991.

RAO, I. M.; KERRIDGE, P. C.. Mineral nutrition of forage Arachis. In: KERRIDGE, P. C.. Biology and agronomy of forage Arachis. Cali: CIAT, p.71-83, 1993.

REIS JUNIOR, R. A.; MONNERAT, P. H.. Exportação de nutrientes nos tubérculos de batata em função de doses de sulfato de potássio. Horticultura Brasileira, Brasília, v.19, n.3, p.360- 364, 2001.

RIBEIRO, P. H.; SILVA, V. M.; TEIXEIRA, A. F. R.. Teores de zinco, cobre, boro, ferro e manganês em composto com esterco bovino e compostos de gliricídia e capim elefante. ENCONTRO LATINO AMERICANO DE INICIACAO CIENTIFICA E XI ENCONTRO LATINO AMERICANO DE POS- GRADUACAO, 15. Anais. São Joé dos Campos: Universidade do Vale do Paraíba, 2011.

SILVA, M. A. G.. Efeito do nitrogênio e potássio na produção e nutrição do pimentão em ambiente protegido. Tese (doutorado) - Universidade de São Paulo, Piracicaba, 1998.
SOUZA, J. L.; RESENDE, P.. Manual de horticultura orgânica. Viçosa: Aprenda Fácil, 2003.

STOCKDALE, E. A.; SHEPHERD, M. A.; FORTUNE, S.; CUTTLE, S. P.. Soil fertility in organic farming systems: Fundamentally different?. Soil Use and Management, v.18, p.301-308, 2002.

TEIXEIRA, V. I.; DUBEUX JUNIOR, J. C. B.; SANTOS, M. V. F.; LIRA JUNIOR, M. A.; SILVA, H. M. S.. Aspectos agronômicos e bromatológicos de leguminosas forrageiras no nordeste brasileiro. Archivos de Zootecnia, Córdoba, v.59, n.226, p.245-254, 2010.

VALENTIM, J. F.; CARNEIRO, J. C.; SALES, M. F. L.. Amendoim forrageiro cv. belmonte: leguminosa para a diversificação das pastagens e conservação do solo no Acre. Rio Branco: Embrapa, 2003.

VELOSO, C. A. C.; MURAOKA, T.; MALAVOLTA, E.; CARVALHO, J. G.. Influência do manganês sobre a nutrição mineral e crescimento da pimenteira do reino (Piper nigrum, L.). Scientia Agricola, Piracicaba, v.52, n.2, 1995.

WERNER, J. C.; MONTEIRO, F. A.; MEIRELLES, N. M. F.. Efeito das adubações com fósforo, potássio e molibdênio mais cobre na consorciação de capim: gordura com centrosema. Zootecnia, v.21, n.2, p.109-134, 1984.

WHITEHEAD, M.. The concepts and principles of equity and health. Copenhagen: WHO, 2000.

A CBPC - Companhia Brasileira de Produção Científica (CNPJ: 11.221.422/0001-03) detém os direitos materiais desta publicação. Os direitos referem-se à publicação do trabalho em qualquer parte do mundo, incluindo os direitos às renovações, expansões e disseminações da contribuição, bem como outros direitos subsidiários. Todos os trabalhos publicados eletronicamente poderão posteriormente ser publicados em coletâneas impressas sob coordenação da Sustenere Publishing, da Companhia Brasileira de Produção Científica e seus parceiros autorizados. Os (as) autores (as) preservam os direitos autorais, mas não têm permissão para a publicação da contribuição em outro meio, impresso ou digital, em português ou em tradução. 